\title{
Oscillatory behaviour of odd order neutral delay dynamic equations on time-scales
}

\author{
Said R. Grace* \\ Faculty of Engineering, \\ Cairo University, \\ Orman, Giza 12221, Egypt \\ Email: srgrace@eng.cu.eg \\ *Corresponding author
}

Department of Engineering Mathematics,

\section{Sandra Pinelas}

Departamento de Ciências Exactas e Naturais,

Academia Militar,

Av. Conde Castro Guimarães,

2720-113 Amadora, Portugal

Email: sandra.pinelas@gmail.com

\section{Ravi P. Agarwal}

Department of Mathematics,

Texas A\&M University-Kingsville,

700 University Blvd., Kingsville,

TX 78363-8202, USA

Email: agarwal@tamuk.edu

\begin{abstract}
We shall establish some new criteria for the oscillation of neutral delay dynamic equations on an arbitrary time-scale.

Keywords: neutral delay dynamic equations; oscillation; time-scale; higher order.

Reference to this paper should be made as follows: Grace, S.R., Pinelas, S. and Agarwal, R.P. (2012) 'Oscillatory behaviour of odd order neutral delay dynamic equations on time-scales', Int. J. Dynamical Systems and Differential Equations, Vol. 4, No. 3, pp.187-197.

Biographical notes: Said R. Grace is a Professor at the Department of Engineering Mathematics in Cairo University, Egypt. He is the author of more than 225 journal articles and five books. He received the PhD degree in 1981 in Mathematics from the University of Saskatchewan, Canada.

Sandra Pinelas is a Professor at the Department of Mathematics in Azores University, Portugal. She is the author of more than 36 journal articles and one book. She received her PhD Degree in 2007 in Mathematics from the Azores University, Portugal.
\end{abstract}

